\title{
Pediatrik Olguda Alışılmadık Bir Pelvik Ağrı Sebebi: Herlyn-Werner-Wunderlich Sendromu
}

\section{An Unexpected Cause of Pelvic Pain in a Pubertal Case: Herlyn-Werner-Wunderlich Syndrome}

\author{
Yasemin Kayadibi, Elmar Bayraktarov, Evrim Özmen, Altay Gezer*, Ibrahim Adaletli \\ istanbul Üniversitesi Cerrahpaşa Tıp Fakültesi, Radyoloji Anabilim Dalı, Istanbul, Türkiye \\ *istanbul Üniversitesi Cerrahpaşa Tıp Fakültesi, Kadın Hastalıkları ve Doğum Anabilim Dalı, İstanbul, Türkiye
}

\section{Özet}

İmperfore hemivajen ile beraber uterovajinal duplikasyon nadir bir müllerian füzyon anomalisidir. Bu kompleks genital malformasyona aynı taraflı renal agenezinin eşlik ettiği durum Herlyn-Werner-Wunderlich sendromu olarak adlandırımaktadır. Pubertal adolesanlarda ve yetişkin kadınlarda klinik prezentasyon genellikle obstrükte hemivajene sekonder hidrometrokolposun yol açtığı kitle etkisi ve pelvik ağııdır. Menstruasyona rağmen gelişen hematokolpos tanıda yanılgıya sebep olabilmektedir. Kesin tanıda altın standart laparotomi olmakla birlikte uterovajinal anatomiyi detaylandırmada pelvik manyetik rezonans görüntüleme (MRG) \%100'e yakın doğruluk göstermektedir. Biz bu olgu sunumunda pubertal dönemde siklik şiddetli pelvik ağrı ile kendini gösteren Herlyn-Werner-Wunderlich sendromu olgusuna ait ultrasonografi (USG) ve MRG bulgularını sunmayı amaçladık. (Haseki Tıp Bülteni 2014; 52: 60-3)

Anahtar Kelimeler: Herlyn-Werner-Wunderlich, hematokolpos, manyetik rezonans görüntüleme, pelvik ağrı, puberte
Uterovaginal duplication with imperforated hemivagina is a rare type of Mullerian anomaly. If ipsilateral renal agenesis is associated with this complex genital malformation, it is called Herlyn-WernerWunderlich syndrome. Clinical presentations of this syndrome include pelvic pain and mass effect due to obstructed hemivagina in pubertal adolescents and adults. Hematocolpos, even after menstruation period, leads to misdiagnosis. Laparotomy is the gold standard for the diagnosis, however, magnetic resonance imaging has an accuracy upto $100 \%$ in evaluating uterovajinal anatomy. In this article, we aimed to present ultrasonographic and magnetic resonance imaging findings in a patient with Herlyn-Werner-Wun derlich syndrome who presented with cyclic pelvic pain. (The Medical Bulletin of Haseki 2014; 52: 60-3)

Key Words: Herlyn-Werner-Wunderlich, hematocolpos, magnetic resonance imaging, pelvic pain, puberty
Yazışma Adresi/Address for Correspondence: Yasemin Kayadibi İstanbul Üniversitesi Cerrahpaşa Tıp Fakültesi, Radyoloji Anabilim Dalı, İstanbul, Türkiye GSM: +90 5362570879 E-posta: yasemin.kurdoglu@istanbul.edu.tr Geliş Tarihi/Received: 08 Temmuz 2013 Kabul Tarihi/Accepted: 03 Eylül 2013
Haseki Tıp Bülteni, Galenos Yayınevi tarafından basılmıştır. The Medical Bulletin of Haseki Training and Research Hospital, published by Galenos Publishing. 


\section{Giriş}

Genitoüriner organların gelişimi embriyolojik yaşamın 6. haftasında başlar. Bu haftada oluşabilecek bir duraksama müllerian kanal anomalilerine neden olabilmektedir (1). Genel popülasyonda müllerian anomalilerin görülme sıklığı yaklaşık \%0.1-3.8 olmakla birlikte rekürren abortus olgularında bu oran \%8-\%10 arasındadır $(2,3)$. Imperfore hemivajen, uterus didelpis ve ipsilateral renal agenezi birlikteliği Herlyn-Werner-Wunderlich sendromu (HWW) olarak bilinmekte olup ilk olarak 1922'de tanımlanmıştır (3). Müllerian anomaliler arasında rastlanma oranı yaklaşık 1/2.000 ile $1 / 28.000$ arasındadır (4). Biz bu yazımızda oldukça nadir rastlanan bir HWW olgusunun ultrasonografi (USG) ve manyetik rezonans görüntüleme (MRG) bulgularını sunmayı amaçladık.

\section{Olgu}

Üç aydan beri düzensiz adet gören ve her adet döneminde şiddetli pelvik ağıı tarif eden 13 yaşında kız hasta pelvik ağıı sebebiyle kliniğimize başvurdu. Hasta virgo olduğu için vajinal muayenesi yapılamadı. Yapılan abdominal USG incelemesinde birbiri ile bağlantısı görülemeyen çift endometriyal kavite, sağ hemifundusta hematometra ve sağ taraflı proksimal vajen lümeninde ileri derecede dilatasyona yol açan hematometrokolpos saptandı (Resim 1). Ek olarak olgunun sağ böbreği izlenmedi. Detaylı anatomik değerlendirme amacıyla yapılan MRG tetkikinde uterus didelfis anomalisi ve mesane posteriorunda, mesaneyi anteriora deplase eden T1 ağırlıkı kesitlerde hiperintens ve T2 ağırlıklı kesitlerde en geniş aksiyel boyutunda 50 mm'ye ulaşan, minör pelvisi dolduran, izo-hipointens hemorajik-proteinöz mayi ile uyumlu kistik yapı mevcuttu. Bu kistik yapı yalnızca sağ taraflı hemiuterusla iştirakli olup atrezik bir vajinal kanal ile sonlanım göstermekteydi. Sol taraf hemiuterus ve endometrial kavite normaldi. Her iki overin görünümü doğal idi. Sağ böbrek MRG'de de saptanamadı ve renal agenezi olarak yorumlandı (Resim 2). Hasta HWW

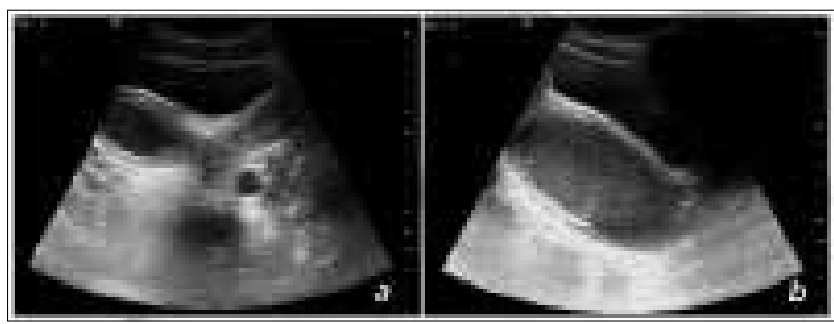

Resim 1. a) B mod ultrason görüntüsünde mesane posteriorunda çift endometrial kavite izlenmektedir. Sağ hemifundus lümeninde hematometra ile uyumlu ekojenik görünüm mevcuttu. b) B-mode ultrason görüntüsünde mesane posteriorunda hematokolposa ait yoğun iç ekolu dilate vajen seçilmektedir tanısı alarak ağrılarını gidermek amacıyla operasyona alındı. Dorsolitotomi pozisyonunda, anestezi altında sağ hemivajen septumu insize edilerek her iki vajina birleştirildi. Sol uterusun drenajının sağlanmasıyla hastanın yakınmaları ortadan kalktı. Post operatif ikinci ayında menstruasyon görmeye başlayan hastanın ilk menstruasyon sonrasında yapılan MRG tetkikinde sağ taraflı hemivajendeki hematokolposun gerilediği izlendi (Resim 3). Hastanın 6 aylık takibinde herhangi bir şikayeti olmadı, menstruasyon siklusları düzenli ve ağrısız idi.

\section{Tartışma}

Müllerian kanalın gelişimi organogenez, füzyon ve septal rezorpsiyondan oluşan 3 aşamada gerçekleşmektedir. Bu aşamalardaki bir duraksama müllerian füzyon anomalilerine neden olmaktadır. Organogenez aşaması kaynaklı patolojiler müllerian agenezi veya unikornat uterus; füzyon aşaması kaynaklı patolojiler bikornat uterus veya uterus didelfis; septal rezorpsiyon aşaması kaynaklı patolojiler ise septat uterustur $(1,5)$. Müllerian kanal anomalilerine \%20-\%25 oranında üriner sistem anomalileri de eşlik etmektedir (6). Yaygın inanılan teoriye göre fetal dönemde Wolf kanalları, Müller kanallarının füzyonunda kılavuzluk görevi üstlenmektedir. Bu teori müllerian anomalilerine üriner sistem anomalilerinin eşlik etme mekanizmasını da açıklamaktadır. Wolf kanalı gelişiminde bir kusur mevcut ise o tarafın böbrek ve toplayıcı sistemi gelişemeyeceği gibi uterusta da füzyon anomalileri meydana gelebilmektedir $(7,8)$. Uterus didelfis müllerian kanalların tam füzyon defekti olmakla birlikte müllerian anomalilerin yaklaşık \%11'ini oluşturur (9). Yaklaşık \%75 oranında transvers

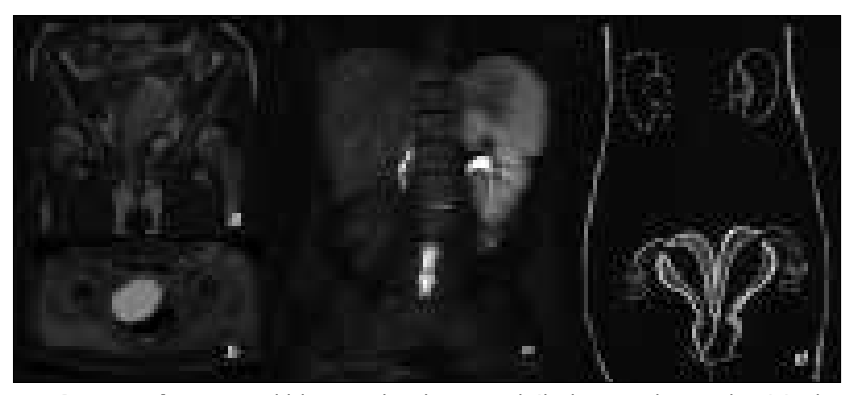

Resim 2. a) T2 ağırlıklı yağ baskısız pelvik koronal MR kesitinde; hemorajik mayi ile dilate vajen seçilmektedir. Vajen lümeninde kan ürünlerine ait hipointens sinyal kayıtları alınmıştır. Vajen superiorunda sağda ve solda iki adet uterus korpusu ve sağda endometriuma ait hiperintensite dikkati çekmektedir.Bu görünüm uterus didelfisi düşündürmektedir. b) T1 ağırlıklı yağ baskılı MR kesitinde, hemorajik mayi ile dilate vajen hiperintens yapı olarak izlenmektedir. c) Koronal yağ baskılı T2 ağırlıklı kesitte sol böbrek normal boyutta ve lokalizasyonda izlenirken sağ böbrek lokalizasyonunda izlenmemektedir. d) Herlyn- Werner- Wunderlich sendromunda anatomiyi anlatan şekil 


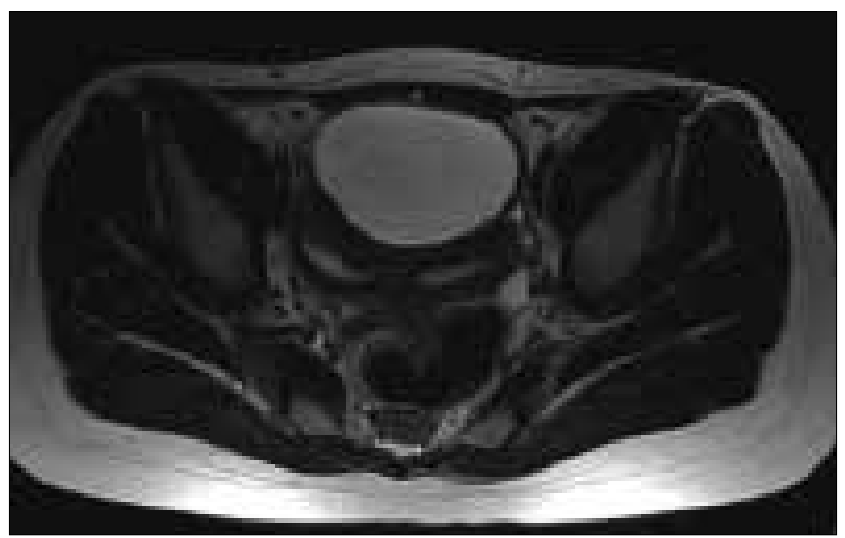

Resim 3. Post op T2 ağırlıklı yağ baskısız aksiyal MR kesitinde hematokolpos görüntüsünün kaybolduğu izlenmektedir. Dolu mesane posteriorunda iki adet uterus korpusu ve endometriumları seçilmektedir

vajinal septum eşlik etmektedir (1). Overlerin gelişiminin müllerian kanal ile ilişkisi bulunmaması sebebiyle bu tip hastalarda ovaryen fonksiyonlar normaldir (10). Obtrüktif hemivajen, uterus didelfis ve ipsilateral renal agenezi birlikteliği HWW sendromu olarak adlandırılır (Resim 2d) (4). HWW sendromu genellikle pubertal dönemde menarşı takiben hematokolposa sekonder gelişen şiddetli pelvik ağrı ve pelvik kitle ile kendini göstermektedir $(11,12)$. Ancak prepubertal dönemde de saptanan olgular bildirilmiştir (13). Piyohematokolpos, piyosalpenks, piyoperitonit gibi enfektif süreçler, retrograd menstruasyona sekonder endometriozis ve pelvik adezyonlar karşılaşılabilecek komplikasyonlar arasındadır (11,12,16-18). Endometriozis gelişimi sıklık pelvik ağrı oluşmunda da rol oynamaktadır. Menstruasyona rağmen gelişen hematokolpos tanıda yanılgıya sebep olabilmektedir. HWW sendromu tamamen semptomsuz da seyredebilmektedir. Karaca ve ark. vajinal septum rezeksiyonu öncesi term gebeliğe ulaşan ve bu döneme dek semptomsuz seyreden bir HWW vakası bildirmişlerdir (14). Tanıda ilk planda USG, BT ve histerosalpingografi kullanılmaktadır. Kesin tanıda altın standart laporotomi olmakla birlikte uterovajinal anatomiyi detaylandırmada pelvis MRG \%100'e yakın doğruluk göstermektedir (15). Tedavi seçenekleri arasında vajinal septumun açık vajinal kanal ile ağızlaştırılması ve hemihisterektomi bulunmaktadır. Vajinostomi vajinal yolla yapılabileceği gibi hastanın ve ailesinin himenin korunmasını istemesi durumunda, komplikasyon gelişen veya uterin yapının düzeltilmesi planlanan olgularda vajinal müdahale yerine laparotomik yaklaşım da tercih edilebilmektedir $(6,16)$. Drenajın sağlanamadığı vakalarda retrograd menstruasyona sekonder gelişebilecek endometriozis riskini azaltmak ve üreme fonksiyonlarını korumak amacıyla cerrahi yaklaşım geciktirilmeden uygulanmalıdır (16-18). Cerrahi tedavinin uygulanamadığı olgularda hematometra ve hematokolpos gelişimini önlemek amacıyla menstruasyon supresif ilaç

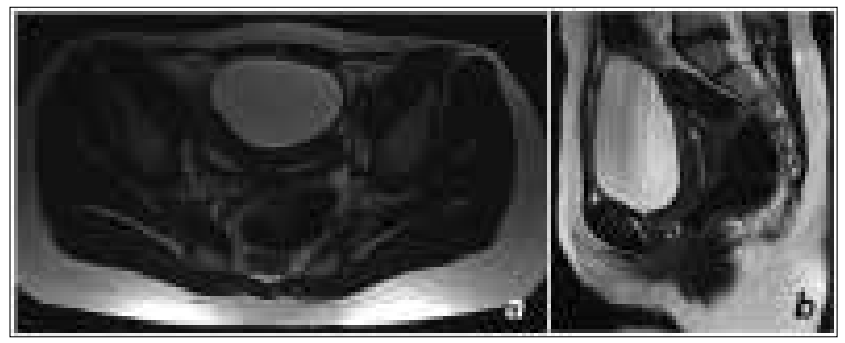

Resim 4. a) Post op T2 ağılıklı yağ baskısız aksiyal MR kesitinde hematokolpos görüntüsünün kaybolduğu izlenmektedir. Dolu mesane posteriorunda iki adet uterus korpusu ve endometriumları seçilmektedir. b) Post opT2 ağırlıklı yağ baskısız sagital MR kesitinde sağ vajeni mesane ve rektum arasında normal kalibrasyonda izlenmektedir. Vajen superior kesimde sağ uterus ile devamlılık göstermektedir

tedavisi uygulanmalıdır. Literatürde cerrahi tedavi görmüş hastalarda yaklaşık \%87 oranında fertilite bildirilmektedir. Gebelik bildirilen opere HWW olgularında patolojik gebelik veya gebeliğe bağlı komplikasyon saptanmamıştır (6). Primer infertilite saptanan olgularda ise mevcut uterin anomaliden ziyade cerrahi tedavi öncesi retrograd menstruasyona sekonder gelişen endometriozis ve intraperitoneal enfeksiyon gibi diğer sebepler düşünülmelidir $(6,18)$.

\section{Sonuç}

Sonuç olarak, özellikle menstruasyon sonrası alt abdominal ağrı ve pelvik kitle yakınmaları olan pubertalprepubertal kızlarda uterus didelfis ve hematokolpos akla getirilmelidir. Preoperatif planlama açısından anotomik yapıların net bir şekilde ortaya çıkarılmasında pelvik MRG önemli rol oynamaktadır. Erken tanı ve tedavi gelişebilecek komplikasyonları önlemekte olup fertilitenin korunmasını sağlamaktadır.

\section{Kaynaklar}

1. Junqueira $B L$, Allen LM, Spitzer RF, Lucco KL, Babyn PS, Doria AS. Müllerian duct anomalies and mimics in children and adolescents: correlative intraoperative assessment with clinical imaging. Radiographics 2009;29:1085-103.

2. Purslow CE. A case of unilateral haematocolps, haematometria, and haematosalpinx. J Obstet Gynaecol Br Emp 1922;29:643.

3. Ashton D, Amin HK, Richart RM, Neuwirth RS. The incidence of asymptomatic uterine anomalies in women undergoing transcervical tubal sterilization. Obstet Gynecol 1988;72:28-30.

4. Del Vescovo R, Battisti S, Di Paola V et al. Herlyn-WernerWunderlich syndrome: MRI findings, radiological guide (two cases and literature review), and differential diagnosis. BMC Med Imaging 2012;12:1-10.

5. Koff AK. Development of the vagina in the human fetus. Contrib Embryol 1933;24:59-91

6. Acién $\mathrm{P}$, Acién $\mathrm{M}$. Unilateral renal agenesis and female genital tract pathologies. Acta Obstet Gynecol Scand 2010;89:1424-31.

7. MiyazakiY, Ebisuno S, UekadoY, Ogawa T, Senzaki A, Ohkawa T. Uterus didelphys with unilateral imperforate vagina and ipsilateral renal agenesis. J Urol 1986;135:107-9. 
8. Sánchez-Ferrer ML, Acién MI, Sánchez del Campo F, MayolBelda MJ, Acién P. Experimental contributions to the study of the embryology of the vagina. Hum Reprod 2006;21:16238.

9. Acien P. Incidence of Müllerian defects in fertile and infertile women. Hum Reprod 1997;12:1372-6.

10. Amesse LS, Ptaff-Amesse T. Congenital anomalies of the reproductive tract. In: Falcone $\mathrm{T}$, Hurd WW, eds. Clinical Reproductive Medicine and Surgery; 2007. p.235-9.

11. Fedele L, Motta F, Frontino G, Restelli E, Bianchi S. Double uterus with obstructed hemivagina and ipsilateral renal agenesis: pelvic anatomic variants in 87 cases. Hum Reprod 2013:28:1580-3.

12. Tong J, Zhu L, Lang J.Clinical characteristics of 70 patients with Herlyn-Werner-Wunderlich syndrome. Int J Gynaecol Obstet 2013;121:173-5.

13. Sanghvi $Y$, Shastri $P$, Mane SB, Dhende NP. Prepubertal presentation of Herlyn-Werner-Wunderlich syndrome: a case report. J Pediatr Surg 2011;46:1277-80.
14. Karaca I, Talar \$̧, Atakan R, Yapça ÖE. Term Gebeliğe Ulaşan Herlyn-Werner-Wunderlich Sendromu: Nadir Bir Olgu Sunumu. Erciyes Med J 2013;35:90-2.

15. Tanaka YO, Kurosaki Y, Kobayashi T, et al. Uterus didelphys associated with obstructed hemivagina and ipsilateral renal agenesis: MR findings in seven cases. Abdom Imaging 1998:23:437-41.

16. Balcı O, Yazıcı F, Mahmoud As, Çapar M. Tek Tarafıı Renal Agenezi ve Tek Taraflı Hematometranın Eşlik Ettiği Bir Uterus Didelfus Olgusu. Selçuk Üniv Tıp Derg 2011;27:164-66

17. Büyükkurt $S$, Sucu $M$, Ürünsak iF, Güzel $A B$, Kadayıfçı $O$. Tek taraflı hematokolpos ve hematometrayla birlikte tam uterovajinal duplikasyon ve aynı tarafta renal agenezi: olgu sunumu. J Turk Soc Obstet Gynecol 2006:3:347-48.

18. Güdücü N, Gönenç $G$, Işçi $H$, Yiğiter $A B$, Dünder I. HerlynWerner-Wunderlich Syndrome-Timely Diagnosis is Important to Preserve Fertility. J Pediatr Adolesc Gynecol 2012;25:11112. 